\title{
Article
}

\section{Evaluating the roles and powers of rail regulatory bodies in Europe: A survey- based approach}

Benedetto, Valerio, Smith, Andrew James and Nash, Chris A

Available at http://clok.uclan.ac.uk/19065/

Benedetto, Valerio ORCID: 0000-0002-4683-0777, Smith, Andrew James and Nash, Chris A (2017) Evaluating the roles and powers of rail regulatory bodies in Europe: A survey-based approach. Transport Policy, 59 . pp. 116-123. ISSN 0967-070X

It is advisable to refer to the publisher's version if you intend to cite from the work. http://dx.doi.org/10.1016/j.tranpol.2017.07.003

For more information about UCLan's research in this area go to http://www.uclan.ac.uk/researchgroups/ and search for <name of research Group>.

For information about Research generally at UCLan please go to http://www.uclan.ac.uk/research/

All outputs in CLoK are protected by Intellectual Property Rights law, including Copyright law. Copyright, IPR and Moral Rights for the works on this site are retained by the individual authors and/or other copyright owners. Terms and conditions for use of this material are defined in the policies page.

\section{CLoK}

Central Lancashire online Knowledge www.clok.uclan.ac.uk

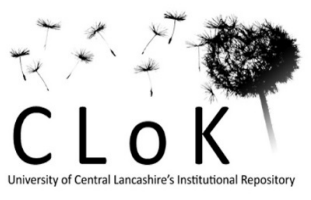




\title{
Evaluating the Roles and Powers of Rail Regulatory Bodies in Europe:
}

\section{A Survey-Based Approach}

Authors: Valerio, Benedetto ${ }^{1,2^{*}}$, Andrew, S.J., Smith ${ }^{3,4}$, Chris, A., Nash ${ }^{5}$

${ }^{1 *}$ Corresponding author. Institute for Transport Studies, University of Leeds, Leeds LS2 9JT, United Kingdom. Contact details: +44 (0)1772 89 4581, tsvb@leeds.ac.uk.

${ }^{2}$ College of Health and Wellbeing, University of Central Lancashire, Preston PR1 2HE, United Kingdom.

3 Institute for Transport Studies, University of Leeds, Leeds LS2 9JT, United Kingdom, A.S.J.Smith@its.leeds.ac.uk.

${ }^{4}$ Leeds University Business School, University of Leeds, Leeds LS2 9JT, United Kingdom.

5 Institute for Transport Studies, University of Leeds, Leeds LS2 9JT, United Kingdom, C.A.Nash@its.leeds.ac.uk.

\begin{abstract}
European railways have been shaped by multiple reforms since the mid-1990s, covering industry structure, market opening and economic regulation. However, the literature has given little attention to the latter; namely the evolution and impacts of economic regulation amongst Europe's railways. This paper fills this gap by providing an up-to-date, bottom-up assessment of current rail regulatory practice in Europe. We develop a survey of economic regulators across Europe, which complements top-down studies by enabling a richer insight into regulatory activity and its impacts. The questionnaire is based on a review of the literature on ideal regulatory characteristics. Our results indicate that European rail regulators, in general, exhibit many of the features of ideal regulation; in particular, independence, resourcing, longevity and expertise, transparency and in turn stability and predictability. However, we find that regulatory bodies could take a more proactive role in shaping track access charges, given their importance in respect of efficient use of the network and maintaining non-discriminatory access. Importantly, there is scope for regulators to play a greater role in regulating the efficiency and quality of infrastructure managers, and potentially becoming more involved in the designing stages of passenger market opening as it emerges.
\end{abstract}

\section{Highlights}

- Unique, up-to-date survey of rail regulatory practice in Europe

- Bottom-up approach complements previous, top-down econometric methods 
- Theoretical basis to the survey: review of ideal regulatory characteristics

- Finds positive correspondence between rail regulatory practice and ideal regulation

- Increased efficiency and market opening role suggested for regulators

\section{Keywords}

Regulation, Railways, Competition, Cost, Structure 


\section{Introduction}

Among the European railway reforms implemented from the 1990s, the introduction, renewal and strengthening of regulatory roles have been of primary importance. Given the aim of the European Commission to turn around the previously stagnating performance of railways through stimulating competition, strong regulation is needed to allow the successful implementation of the reform programme. The natural monopoly element of the infrastructure requires regulation to ensure that it is cost efficient and delivers the required investment and quality of network. Its prices (for access to the infrastructure) should also be set in accordance with economic principles and it is crucial that new entrants can gain fair access to the infrastructure in order to stimulate competition (nondiscrimination). Regulatory reform therefore also goes hand in hand with the Commission's legislation targeting vertical separation (either with infrastructure and operations in separate legal entities, or at least in separate divisions of the same parent company). To play an effective role, economic regulators need to be independent both of government (given its role as funder and owner of the incumbent rail operator and infrastructure managers in most EU countries) and railway companies.

Nevertheless, these regulatory reforms have attracted little attention in the literature on the impacts of railway reforms, which has concentrated much more on structural and market interventions. Those studies that have looked at the impact of regulatory reforms in Europe have focused on top-down econometric methods, introducing regulatory variables into an econometric cost function. Some studies have adopted relatively simple measures of regulation (i.e. dummy variables capturing the presence or not of an independent economic regulator (e.g. Wetzel, 2008)). Smith et al. (2015), build on this approach by introducing a multi-dimensional regulation index into a translog cost system.

Smith et al. (2015) demonstrate that over the period of their sample - 2002-2011 - the strength of economic regulation in Europe's railways increased considerably, as measured by their regulation index, which extracts the regulatory related aspects of the Rail Liberalisation Index reports (IBM and Kirchner, 2002, 2004, 2007 and 2011). Over that time the reforms had a beneficial impact 
on costs, particularly when combined with vertical separation. However, even this improvement was not considered adequate by the European Commission, which set out further reforms in the 2012 Recast of the First Railway Package (European Parliament and Council Directive 2012/34/EC, "Recast" hereafter). These reforms focused particularly on ensuring regulatory independence (from government) and giving regulators increased powers (see Smith et al., 2015).

A clear gap in the literature, therefore, is an up-to-date (post 2012 Recast), in-depth, bottomup documentation and assessment of rail regulatory practice in Europe, which is the focus of this paper. We undertake such an appraisal through a survey of economic regulators across Europe, thus complementing previous top-down, econometric studies. In particular, it allows a richer insight into regulatory activity and the mechanisms by which regulators are influencing (or not) the activities of firms and the resulting impacts on final outcomes in the sector.

The novelty of this paper can be summarised as follows. Firstly, our study of the regulatory role expands on the analysis of previous studies in order to account not only for the independence of the regulators (the focus of most previous work, with the exception of Smith et. al., 2015), but also for the increasing number of powers assigned to these bodies. These regulatory trends are analysed in order to capture potential patterns at the European level. Secondly, for this purpose, an extensive review of what best describes an "ideal rail regulator" is carried out. The findings of this literature review crucially inform the design of a questionnaire sent to industry actors, ensuring updated firsthand evidence on the current trends regarding rail regulation. Survey-based approaches for examining regulatory frameworks have previously been used in transport (e.g. Beria et al., 2015, for motorways). Thirdly, our qualitative, bottom-up approach complements the top-down econometric analysis carried out in Smith et al. (2015) as noted. Finally, our work brings the analysis of regulatory activity up-todate, covering the period post the 2012 Recast.

The remainder of the paper is structured as follows. Section 2 first explains the rationale for rail regulation in more detail, before summarising the relevant European legislation. Section 3 includes a review of the literature on what constitutes an "ideal economic regulatory body" in railways. The related findings are key to the design of the questionnaire on the role of rail regulation, 
described in Section 4, together with details on the participants and collection of data. Results emerging from the questionnaire are reported and discussed in Section 5, and concluding remarks are presented in Section 6.

\section{Background on legislation on rail regulators}

This section is divided into two parts. We first set out the rationale for regulating Europe's railways. In the second part we briefly review the relevant European legislation pertaining to rail regulation.

\subsection{Why regulate Europe's railways?}

Regulation might be expected to play an important role in railway markets for several reasons. The implementation of vertical separation in a number of European countries involves the emergence of important interactions occurring between disjointed interfaces, namely the infrastructure managers on one side, and the railway undertakings on the other. These interactions are typically related to investment strategies, capacity allocation and timetabling, as well as real-time operations, creating an interdependent environment for railway undertakings, infrastructure managers and (at times) governments. Here we use the term vertical separation to mean full, legal separation of rail infrastructure from train operations. The intermediate position, the "holding company" model, has also been adopted in several European countries, and refers to a situation where infrastructure and operations are organised into separate divisions within the same parent group.

If with vertical integration (and to some extent with the holding company model), transaction costs are argued to be small because the interactions are between entities sharing the same business interests, with vertical separation these costs are likely to reach greater levels, since the parties involved are placed on opposing positions, and the possibility of reaching compromises is inevitably reduced. It should be noted that whilst direct transaction costs may be small in railways (see Merkert et al., 2012), the greater problem probably lies in the costs associated with misaligned incentives and the (perhaps bad) decisions resulting from this (see van de Velde et al., 2012). In this scenario, regulators could act as impartial third parties, attempting to minimise transaction costs and the 
associated wider problems of misalignment of incentives. To be effective, the regulatory role should be independent of governmental or, more generally, political influence, when the negotiations involve railway undertakings or network managers controlled (directly or indirectly) by government.

In these unbundled contexts, regulators can also help improve rail system efficiency. Infrastructure managers in separated systems may be less incentivised to be efficient in contrast with more integrated models, where the efficiency achieved by the infrastructure managers has wider implications for the financial performance of the parent group. In separated models, this shared interest tends to fade, and here the regulator may need to step in to exert the necessary pressure on infrastructure managers. This potential role of the regulator is also envisaged by the Recast (section 2.2). This sees regulators potentially playing a greater role in incentivising and enforcing improved efficiency and quality performance.

Whilst the control of infrastructure managers' performance and efficiency produces direct effects on costs on the part of the regulators, monitoring non-discrimination and promoting and strengthening competitive conditions impact indirectly on the efficiency of a railway system. Through the resolution of disputes on competition and, more generally, the prevention of practices deviating from this objective, regulators might play a role in ensuring that potentially more efficient players are allowed to enter the railway arena, thus also putting pressure on the incumbent to become more efficient. However, to date, whilst there has been competition in freight markets in Europe, this has been much less prevalent in passenger markets.

Institutionally, in order to obtain these goals, three rail regulatory models have been developed in Europe (see IBM Business Consulting Services, 2006; Crozet et al., 2012): the ministry model (Model 1), the railway authority model (Model 2), and the special regulatory authority model (Model 3). While Model 1 was made illegal by the Recast (see section 2.2), Model 2 has gradually lost popularity in favour of Model 3, now utilised in 20 countries, as opposed to 7 countries in 2006 (IBM Business Consulting Services, 2006).

\subsection{Overview of rail regulation legislation in Europe}


Railway reforms implemented since the mid-1990s have covered multiple and diverse aspects, focusing on the structure, regulation, and competitive conditions of the market. From a legislative point of view, this stimulus has produced Three Railway Packages ${ }^{1}$, one Recast and the proposal for a Fourth Railway Package (COM, (2013) 25, final). This section concentrates on those legislative acts altering regulatory positions, and in particular the Recast.

In 2012, the Recast determined an important legislative break-through, attempting to resolve many problems in European regulatory practice (see Smith et al., 2015). Particular problems included the scarce level of competition faced by national incumbents, inadequate regulatory independence and powers, and modest investment in railway infrastructure, with associated infrastructure quality issues.

Specifically, competences were extended in order to cover the access to and charging for railway services (Article 56), political independence was reinforced to ensure that regulators were no longer residing within transport ministries (Article 55) and impactful activities such as investigations reinvigorated (Article 57). Importantly, new powers associated with the monitoring and enforcement of infrastructure managers' performance and efficiency were granted ${ }^{2}$, providing the regulators with the possibility to require relevant data (Article 56).

Given the above, extensive regulatory developments, it is important to determine how far the legislation is being implemented in practice. Before turning to discuss our survey method, we first consider what an ideal regulator might look like, based on the literature. This review, together with the provisions of the Recast, provides the basis for the questions included in our survey.

\section{Literature review on ideal rail regulator characteristics}

1 First Railway Package: European Parliament and Council Directives 2001/12/EC, 2001/13/EC and 2001/14/EC.

Second Railway Package: European Parliament and Council Directives 2004/49/EC, 2004/50/EC, 2004/51/EC and Regulation (EC) No.881/2004.

Third Railway Package: European Parliament and Council Directives 200758/EC, 2007/59/EC and Regulations (EC) Nos. 1370/2007, 1371/2007, 1372/2007.

${ }^{2}$ Though the legislation states that this role could also be carried out instead via a multi-annual contract between infrastructure managers and governments. 
The regulatory role in rail implies multiple characteristics that have been little analysed by the literature. In order to close this gap, this section will provide a review of those characteristics which may be considered ideal for a rail (or transport) regulator.

Starting with general regulation theory, Fleck (2000) argues that the emphasis should not be placed on the automatic creation of bodies which elsewhere have guaranteed the success of the reforms, but on their staggered establishment depending on the different development stages of a particular system. This implies that a railway regulator may not be required until the market has reached a certain level of competition. The relevance of the context in regulation is also stressed by Gassner and Pushak (2014), who point out the necessity to adapt regulatory structures to the economic, political and sectoral conditions in which the agency would operate. Relevantly, this paper aims to embody context within the analysis wherein various different national characteristics coexist.

Specifically to railways, an important study was produced following an OECD Round Table discussion of experts on the role of economic regulators (OECD/ITF, 2011). Central in these references is the focus on the significance of independence, which in turn depends on several factors. One of the primary objects of the regulator should be the pursuit of non-discrimination, connected with situations in which particular operators enjoy advantageous conditions for the access to relevant infrastructure. To achieve this, the regulator needs to be provided with appropriate human and financial resources and be accountable for its decisions (and its role and responsibilities need to be distinct from those of government or other agencies); and to guarantee independence from government, regulators should be totally separate from transport ministries. The way the regulator reaches its goals is ideally transparent, publicly displaying the process and the results that substantiate decisions. Minimising the frequency of modifications in relation to infrastructure or transport services, and avoiding bowing to short-term political aims, confers stability and predictability. In addition, an ideal regulator would be able to intervene on issues on its own initiative (and not only on request), thereby growing autonomous capabilities. Lastly, and observing another network industry like telecommunications (OECD, 2000), regulatory oversight is better achieved by a collegiate body 
(i.e. a board) rather than by a single person, and the related members should maintain their roles only for fixed terms.

In addition to the key requirements for independence from government, the Recast now confers on rail regulators powers regarding the monitoring of access to and charging system of the pertaining railway market, with a view to generating adequate levels of contestability and competition. Also, the possibility of requesting data and information on accounting documentation, track access charges and financial performance of the infrastructure managers is configured as a relevant regulatory power. The formalisation of an effective sanctioning scheme should be seen as essential as well.

Some of the above aspects have also been investigated by the Rail Liberalisation Index reports produced by IBM and Kirchner (2002, 2004, 2007 and 2011). These studies examine the state of the liberalisation processes in European countries, constructing indices and formulating rankings. Some of the drivers selected by those authors attest the adequacy of the previously described findings, such as the general aspects of the authority (including elements like independence, accountability and transparency), the object of the regulation (for instance, the responsibilities deriving from different types of inspections), and its powers (involving the possibility of imposing coercive means). Another important study on rail regulation was produced in 2006 (IBM Business Consulting Services, 2006), where a survey was conducted in order to assess the regulatory conditions of rail network access in Europe. The areas therein investigated (such as general powers, scope and organisational aspects of the regulators) are also covered in our survey, which aims to update those results by accounting for developments during the last decade, as well as complementing the research on this field by including those characteristics describing an ideal rail regulator.

The above discussion on the key features of an ideal rail regulator inform our questionnaire (see section 4), ultimately targeting the following research questions. How are European rail regulators performing in terms of these ideal characteristics? What are the current regulatory trends characterising European railway systems?

\section{Questionnaire design and data}


The structure of the questionnaire, based on the above literature review, is set out below (Table 1). The 8 key areas reflecting the literature on what represents an ideal regulator are listed in column 1, and detailed in column 2. Column 3 highlights which participants (regulators and/or regulatees $^{3}$ ) were involved in relation to the 8 key areas. The first key area, related to the regulator's position in the rail system, captures two aspects. First, the degree of experience, and in turn commitment, of the regulator, which is argued to be one of the ideal characteristics. Focus is therefore placed on the longevity of the regulator and major changes in its responsibilities in recent years. The second aspect is concerned with gaining information on the extent of competition in the relevant railway markets (this provides contextual information, rather than being concerned with ideal characteristics).

Table 1 Key areas of the questionnaire

\begin{tabular}{|c|c|c|c|}
\hline \multirow[t]{2}{*}{ Key areas } & \multirow[t]{2}{*}{ Purposes } & \multicolumn{2}{|c|}{ Addressed to } \\
\hline & & Regulators & Regulatees \\
\hline 1. Positioning in the market & $\begin{array}{l}\text { Historical evolution of the regulator } \\
\text { and competition levels of passenger } \\
\text { sub-markets }\end{array}$ & $\checkmark$ & \\
\hline 2. Stability and predictability & $\begin{array}{l}\text { Legislative and operational } \\
\text { independence from government } \\
\text { and other bodies, while promoting } \\
\text { conditions for long-term planning }\end{array}$ & $\checkmark$ & \\
\hline 3. Non-discrimination & $\begin{array}{l}\text { Ensuring fair access for operators } \\
\text { when accessing the infrastructure }\end{array}$ & $\checkmark$ & $\checkmark$ \\
\hline 4. $\quad$ Distinct responsibilities & $\begin{array}{l}\text { Avoiding overlapping of roles and } \\
\text { accountability between regulator } \\
\text { and government (or other agencies) }\end{array}$ & & $\checkmark$ \\
\hline 5. Human and financial resources & $\begin{array}{l}\text { Appropriate means to meet } \\
\text { regulatory objectives }\end{array}$ & $\checkmark$ & \\
\hline 6. Transparency & $\begin{array}{l}\text { Ensuring the accountability of the } \\
\text { regulator }\end{array}$ & & $\checkmark$ \\
\hline 7. Pro-activity and effectiveness & $\begin{array}{l}\text { The extent of autonomous powers } \\
\text { for investigations and interventions }\end{array}$ & $\checkmark$ & $\checkmark$ \\
\hline 8. $\quad$ System efficiency & $\begin{array}{l}\text { Accessing and analysing data on } \\
\text { infrastructure managers' quality } \\
\text { and efficiency }\end{array}$ & $\checkmark$ & $\checkmark$ \\
\hline
\end{tabular}

\footnotetext{
${ }^{3}$ The sub-set of regulatees includes infrastructure managers and railway undertakings.
} 
In relation to stability and predictability (area 2), the questions specifically investigate the regulator (or regulatory board) terms of appointment and decision making processes. The number of board members, the duration of appointment and potential re-appointment, and the voting system implemented in order to take decisions are examined, together with questions on whether governmental guidance affects the regulator's decisions and independence.

Non-discrimination (area 3) represents a broad key area of regulatory activity. Here the questionnaire explores the existence and extent of discriminatory situations connected with several railway aspects (such as track; rolling stock; highly specialised staff). The capability of the regulator to respond to these problems is assessed, as well as the number of complaints received. A further section includes the analysis of framework agreements, attempting to establish both their proportion in respect to total capacity and which operators are involved.

The fourth key area pertains to the distinction of responsibilities between the regulator and the government (or other agencies): here questions investigate the connections between railway undertakings and the body (or bodies) issuing licences, safety certificates and vehicles certificates, and on the degree of independence of the regulator from political influence in respect of these matters.

The adequacy of available human and financial resources is explored in the fifth key area. Questions here assess the number and backgrounds of the staff employed by the regulatory agency and attempt to detect which actors contribute to funding the regulatory activities, also exploring whether these financial contributions are deemed sufficient.

The sixth key area, on transparency, consists of questions on the clear and public specification of regulatory decisions and processes. These involve diverse aspects, including the regulator's competence and powers, the issuing of licences, safety certificates and homologation (approval) of vehicles, and the allocation of capacity (together with the related conflicts resolution).

Within pro-activity and effectiveness, regulatory powers on the approval of track access charging schemes are examined. Further queries concern the legal and financial effects of regulatory decisions, determining whether these are binding and whether regulators are able to impose penalties. 
The last key area refers to important powers conferred on regulators by the Recast, especially in relation to the identification of any regulatory or other mechanisms in place to incentivise efficiency. Questions attempt to define the role played by regulators in monitoring and enforcing the quality and efficiency of the infrastructure managers' performance, as well as whether data on costefficiency and quality of service can be accessed.

The questionnaire was sent to regulators, infrastructure managers, and railway undertakings. Two versions of the questionnaire were designed: one for regulators, and one for infrastructure managers and railway undertakings. These versions differ in terms of the individual questions (or whole key areas) selected, whose exclusion or inclusion seek to avoid uninformed answers and to prevent potentially biased responses. This can be seen in respect to the questions on regulatory board terms of appointment and structure, only addressed to regulators, as the regulatees may not be able to possess the relevant information on those points. Biased responses could emerge in relation to the independence of political influence or transparency-related queries: it appears intuitive that regulators may overestimate the level of independence of political influence or transparency of their processes and decisions, while the set of potential regulatees may provide more realistic answers. This dichotomous approach importantly involves counterparties which interact with conflicting interests and thereby are able to offer objective information.

Moving to the list of participants involved, contacts were obtained from the Community of European Railway and Infrastructure Companies (CER) Economics Group and the Independent Regulators' Group - Rail (IRG) Charges Working Group. Presentations took place in order to describe the project to both groups and 17 regulators were eventually contacted, obtaining 14 responses, which correspond to a highly satisfactory $82 \%$ response rate. The focus of the remainder of the paper is mostly placed on the regulators' responses as the participation of infrastructure managers and railway 
undertakings was limited, with the latter confined to incumbents rather than new entrants ${ }^{4}$. The full list of regulators who provided their responses is displayed in Table 2.

A note on the methodological approach needs to be made. Given the confidentiality of the information provided, the related assessment is not aimed to single out individual countries, but on identifying general Europe-wide trends from an aggregate examination of the findings. This examination is extensively presented in the following Section.

Table 2 List of participating regulators

\begin{tabular}{ll}
\hline Belgium & Regulatory body \\
\hline Finland & $\begin{array}{l}\text { Regulatory Service for Railway Transport and for Brussels Airport } \\
\text { Operations }\end{array}$ \\
\hline France & Finnish Transport Safety Agency \\
\hline Germany & Autorité de régulation des activités ferroviaires et Routières \\
\hline Greece & Bundesnetzagentur \\
\hline Italy & Regulatory Authority for Railways \\
\hline Luxembourg & Autorità di Regolazione dei Trasporti \\
\hline Netherlands & Institut Luxembourgeois de Régulation \\
\hline Norway & Authority for Consumers \& Markets \\
\hline Poland & Norwegian Railway Authority \\
\hline Slovenia & Office for Rail Transport \\
\hline Sweden & Post and Electronic Communications Agency of the Republic of \\
\hline Switzerland & Slovenia \\
\hline United Kingdom & Swedish Transport Agency \\
\hline
\end{tabular}

Finally, the questionnaire was sent out in October 2014 and all responses were received by August 2015.

4 The following 6 infrastructure managers and railway undertakings responded to the questionnaire: ÖBBHolding AG from Austria; NMBS / SNCB from Belgium; VR-Group Ltd from Finland; Ferrovie dello Stato Italiane S.p.A. from Italy; Polish State Railways - JSC from Poland; and SBB AG from Switzerland. 


\section{Results and discussion}

A summary of selected regulators' responses is provided in Table 3. Regulators' responses will be predominantly illustrated as the regulatees' responses tend to confirm the evidence of the regulators. For areas 4 and 6 , for the reasons set out, these questions were only asked to regulatees (hence they do not appear in Table 3), and their responses are discussed in the text for these areas.

The positioning in the market (area 1) defines the experience of the regulator and the major changes undertaken in recent years. The majority of regulators have accumulated an extended operational longevity, at times over 15 years. In particular, 11 regulators out of 14 have more than 5 years of experience, indicating that these bodies seem to have reached a stable position in the industry which, on paper, may have contributed to provide them with an appropriate level of credibility and commitment. This is also identifiable by looking at recent changes at national level to regulatory responsibilities which, on the basis of the responses received from 11 regulators (out of 14), all point to an expansion of the powers of regulators, rather than restricting their remits.

In terms of the configuration of the passenger market, the related results do not seem to be particularly encouraging from the point of view of competition. The proportion of the passenger market covered by public service routes (in passenger-km) is on average equal to approximately $77 \%^{5}$, and direct awards represent the predominant method of allocation: regulators' responses (from 14 countries) indicate that in 6 countries, direct awards are the only procedure utilised, while in another 2 countries the related implementation is alternate with tendering procedures, which only play a marginal role. Only in 2 countries in our sample is competitive tendering the norm. Also, regulators only rarely play a role in the designing stages of the tendering procedures. Overall, utilising direct awards is argued to restrict the level of contestability by limiting the number of competitors for specific public service routes, which instead may be more efficiently allocated by tendering procedures. Nevertheless, the choice of formalising a direct award may be due, among other reasons, to the lack of newcomers able to rival the incumbent, which is the case for several domestic markets.

\footnotetext{
${ }^{5}$ This question was pre-answered by using 2012 data and, in some cases, was corrected by the regulators with more recent information. The differences are not large, confirming a constant trend in this area.
} 
Table 3 Summary of selected responses from regulators (covering areas 1-3; 5, 7 and 8) - Sample size: N=14

\begin{tabular}{|c|c|c|c|c|c|c|}
\hline & Key area & Issue & Yes & No & Don't know & Detailed response \\
\hline \multirow[t]{3}{*}{1.} & \multirow[t]{3}{*}{$\begin{array}{l}\text { Positioning in the } \\
\text { market }\end{array}$} & Experience of regulator & & & & $\begin{array}{l}\text { More than } 5 \\
\text { years }(11) ; \text { Less } \\
\text { than } 5 \text { years }(3)\end{array}$ \\
\hline & & $\begin{array}{l}\text { Procedures for } \\
\text { allocation of routes } \\
\text { under public service } \\
\text { contracts }\end{array}$ & & & 4 & $\begin{array}{l}100 \% \text { direct } \\
\text { awards (6); } \\
\text { Direct awards } \\
\text { and tendering (2); } \\
100 \% \text { tendering } \\
(2)\end{array}$ \\
\hline & & $\begin{array}{l}\text { Actual passenger } \\
\text { competition in routes } \\
\text { not covered by public } \\
\text { service contracts }\end{array}$ & 5 & 3 & 2 & $\begin{array}{l}\text { Not legally } \\
\text { permitted (4) }\end{array}$ \\
\hline \multirow[t]{5}{*}{2} & \multirow[t]{5}{*}{$\begin{array}{l}\text { Stability and } \\
\text { predictability }\end{array}$} & $\begin{array}{l}\text { Individual regulator or } \\
\text { regulatory board }\end{array}$ & & & & $\begin{array}{l}\text { Individual } \\
\text { regulator ( } 7) \text {; } \\
\text { Regulatory board } \\
\text { (7) }\end{array}$ \\
\hline & & $\begin{array}{l}\text { Fixed-term } \\
\text { appointment of } \\
\text { regulator }\end{array}$ & 11 & 3 & & \\
\hline & & $\begin{array}{l}\text { Majority voting for } \\
\text { regulatory board's } \\
\text { decisions }\end{array}$ & 5 & & 2 & $\begin{array}{l}\text { Individual } \\
\text { regulator decides } \\
(7)\end{array}$ \\
\hline & & $\begin{array}{l}\text { Appointment of } \\
\text { individual regulator or } \\
\text { members of regulatory } \\
\text { board }\end{array}$ & & & 2 & $\begin{array}{l}\text { By the } \\
\text { government (10); } \\
\text { Others (2) }\end{array}$ \\
\hline & & $\begin{array}{l}\text { Governmental } \\
\text { guidance on regulatory } \\
\text { decisions }\end{array}$ & 1 & 11 & 2 & \\
\hline & Non-discrimination & $\begin{array}{l}\text { Complaints received by } \\
\text { the regulator (on } \\
\text { average in a one-year } \\
\text { period) }\end{array}$ & & & 3 & $\begin{array}{l}\text { Less than } 5 \\
\text { complaints per } \\
\text { year (8); More } \\
\text { than } 5 \text { complaints } \\
\text { per year (3) }\end{array}$ \\
\hline & & $\begin{array}{l}\text { Favouring certain RUs } \\
\text { when disruptions occur }\end{array}$ & 4 & 9 & 1 & \\
\hline \multirow[t]{2}{*}{5 . } & $\begin{array}{l}\text { Human and } \\
\text { financial resources }\end{array}$ & Number of employees & & & 1 & $\begin{array}{l}\text { More than } 10(4) \text {; } \\
\text { Less than } 10(9)\end{array}$ \\
\hline & & $\begin{array}{l}\text { Adequacy of financial } \\
\text { resources }\end{array}$ & 10 & 3 & 1 & \\
\hline \multirow{3}{*}{\multicolumn{2}{|c|}{$\begin{array}{ll}\text { 7. } & \text { Pro-activity and } \\
\text { effectiveness }\end{array}$}} & $\begin{array}{l}\text { Approval of all track } \\
\text { access charging } \\
\text { schemes }\end{array}$ & 5 & 8 & 1 & \\
\hline & & $\begin{array}{l}\text { Legally binding } \\
\text { decisions by regulator }\end{array}$ & 14 & & & \\
\hline & & $\begin{array}{l}\text { Regulator's possibility } \\
\text { of imposing penalties }\end{array}$ & 11 & 3 & & \\
\hline
\end{tabular}




\begin{tabular}{|c|c|c|c|c|c|}
\hline Key area & Issue & Yes & No & Don't know & Detailed response \\
\hline \multirow[t]{3}{*}{ 8. System efficiency } & $\begin{array}{l}\text { Regulator's role in } \\
\text { monitoring and } \\
\text { enforcing the quality } \\
\text { and efficiency of the } \\
\text { infrastructure manager }\end{array}$ & 4 & 9 & 1 & \\
\hline & $\begin{array}{l}\text { Regulator's possibility } \\
\text { of requiring data on } \\
\text { cost-efficiency and } \\
\text { quality of service from } \\
\text { the infrastructure } \\
\text { manager }\end{array}$ & 4 & 7 & 1 & $\begin{array}{l}\text { Individual cases } \\
\text { (2) }\end{array}$ \\
\hline & $\begin{array}{l}\text { Body regulating the } \\
\text { performance and } \\
\text { efficiency of the } \\
\text { infrastructure manager }\end{array}$ & & & 4 & $\begin{array}{l}\text { Regulator (1); } \\
\text { Regulator and } \\
\text { government (1); } \\
\text { Government (7); } \\
\text { Safety authority } \\
\text { (1) }\end{array}$ \\
\hline
\end{tabular}

A further question addressed to regulators concerns the existence of open access conditions for non-public service routes in the domestic passenger market, excluding cases where international services compete with domestic services. While open access is legally permitted in 8 countries (out of 14), in only 5 of them does this actually occur, possibly attesting that lack of competitors previously mentioned. Moreover, these scenarios also help our understanding of the extent to which regulators can indirectly act on promoting competition, an aspect that will be further analysed later.

The second key area (on stability and predictability) determines how the regulators function in terms of appointment, structure and decision-making. The regulators' sample is equally divided in relation to the presence of either an individual regulator ( 7 countries) or a regulatory board (remaining 7 countries). The stability of the appointment is guaranteed in 11 countries (fixed-term contracts), with an average duration per term equal to approximately 5.45 years. In reality the overall appointment may last longer, as these positions are renewable once in 6 countries, and more than once in 3 countries. These results seem to suggest the avoidance of frequent modifications on the part of regulators, who have the possibility of determining their activities with a long-run perspective. Though the picture therefore seems positive here, it should be noted that the possibility of reappointment ( 2 regulators even indicated that no limit exists in the possibility of re-appointment) may 
determine a prolonged, and potentially detrimental, situation where regulatory power remains in the same hands for many years.

In our sample, the majority of the board members are employed full-time, indicating strong regulatory commitment to other industry actors. The boards, on average, consist of 4.5 members. Decisions, apart from the 7 cases where an individual regulator is present, are taken by majority voting in 5 countries $^{6}$. The procedure for the board's appointment is equivalent for most regulators, with the government selecting board members in 10 countries (out of 14). These questions lead to the examination of how the regulator and the government interact. Only 1 regulator included in the sample, when taking decisions, seems to have the obligation to take into account governmental guidance: also, from the answers received, governmental instructions appear to be either rare or not binding. Naturally, this detachment from political aims represents an important requirement for the regulatory autonomy that, according to our results, is widespread across Europe.

The activities substantiating independence are explored further by looking at the answers on non-discrimination issues (area 3), which involved all the participants (regulators and regulatees) to different extents. Perhaps surprisingly, infrastructure managers and railway undertakings have not detected any discriminatory problems connected to a wide range of railway areas ${ }^{7}$. It should be noted however that the railway undertakings surveyed are incumbents, and potentially suffer to a smaller extent from these problems as opposed to newcomers. In addition, regulators' promptness on tackling related problems is considered satisfactory by 4 regulatees (out of 6$)^{8}$. In reality, this promptness has been tested in a very small number of cases in several countries: indeed 8 regulators (out of 14) receive less than 5 complaints per year (on average), and 3 of them have indicated that no complaint was ever lodged. Nonetheless these responses, by offering a valuable snapshot of the current role played by regulators in railways, allow us to appreciate the wider range of powers and activities these

\footnotetext{
${ }^{6}$ This information was not available for 2 countries in which a regulatory board is present.

${ }^{7}$ These are: track, rolling stock, highly specialised staff, use of electrical supply equipment for traction current, refuelling facilities, freight terminals, marshalling yards, train formation facilities, storage sidings, depots, passenger stations, or any additional area.

${ }^{8}$ In relation to the 2 remaining countries, in one case problems concerning the timeline of the regulatory processes were highlighted, while in the other case no information was available.
} 
bodies now enjoy, if compared with the limiting conditions observed at the outset of the reforming season.

As mentioned previously, area 3 covers further questions on potential discriminatory issues arising from disruptions or when framework agreements are stipulated. The minimisation of discriminatory practices seems to emerge when the regulators are asked about the presence of railway undertakings somehow favoured in case of disruptions: only 4 regulators (out of 14) indicate this to happen, determining a priority treatment especially for passenger transport. Lastly, as documented by the responses collected from both regulators and regulatees, framework agreements between the infrastructure managers and the railway undertakings are characterised by moderate diffusion across Europe: in most of the considered countries a threshold has been determined, but only in 4 countries (out of 15 , the whole sample of countries involved in the questionnaire ${ }^{9}$ ) do framework agreements actually cover more than $10 \%$ of the overall capacity. Given the possibility for infrastructure managers to assign priority to framework agreements when deciding on the allocation of capacity, these results seem to attest that potentially discriminatory practices in this field are rather infrequent. In general, discrimination does not seem to be considered a problem by the infrastructure managers and railway undertakings in our sample, and regulators appear to play a proactive role when the need arises (in terms of responses to lodged complaints). It should be noted that our sample does not include new entrant railway undertakings who may have given different answers on this question

The autonomy of the regulators is verified by the responses related to the key area on the distinction of responsibilities (area 4), for which only regulatees were questioned. In 5 countries (out of 6), collusive relationships between railway undertakings and bodies issuing licences, safety certificates and vehicles certifications were absent. For the remaining country, the provided answer is inconclusive on this point. Importantly, a general awareness of the independence of the regulator appears to emerge: all 6 infrastructure managers and railway undertakings stated that governments do

\footnotetext{
${ }^{9} 15$ is the total number of countries analysed in our questionnaire, taking into account the country of origin of all participants.
} 
not influence regulatory decisions and are able to identify the source of the regulator's independence, typically determined by the legislation.

The responses to questions on human and financial resources (area 5) show that, in terms of full-time equivalent, 266.8 employees work across 13 countries $^{10}$ for the regulatory bodies on railway economic regulations only (excluding safety and interoperability). Comparing this result with the data provided in 2006 by IBM's report on rail regulation in Europe ${ }^{11}$ (IBM Business Consulting Services, 2006), the number of staff employed has nearly doubled: in particular, 3 regulatory bodies which had no staff in 2006, have now employed personnel, even though only 4 regulators (out of 14) have more than 10 employees. The backgrounds of the personnel are rather diverse, mainly associated with economic and legal, but also involving rail industry, engineering and administrative expertise.

The capability of hiring new staff does, however, seem to be limited for 3 regulators (out of 14), who indicated inadequate resourcing. These resources derive from two sources: funding is provided fully by the government for 8 regulators, fully by the industry for 5 , and by both for the remaining 1. In general, the majority of regulatory bodies have not indicated problems with the amount of human and financial resources available, and the growing trend in the number of staff seems to corroborate this. Nevertheless, the financial difficulties affecting 3 regulators are not to be underestimated, producing warnings especially for those contexts where government funding may be restricted by fiscal constraints.

The regulators' efforts on transparency (area 6) have reached appropriate levels, according to the responses given by infrastructure managers and railway undertakings only. When asked about the transparency of the regulators' competence and processes, and the procedures for licensing, safety certificates, approval of vehicles, and the allocation of capacity, the participants expressed positive views, also indicating the sources where the related explanatory documentation is available ${ }^{12}$. A negative area concerns the presence and monitoring of annual reports: the 6 responses from

\footnotetext{
${ }^{10}$ One regulator did not answer to this question.

${ }^{11}$ According to the IBM report, the number of employees involved in rail regulation in 2006 was equal to 144 (in this sample). Only a part of staff dealt with regulatory issues full-time, but the exact proportion was not specified.

${ }_{12}^{2}$ Only one participant identified two areas that need better specification.
} 
infrastructure managers and railway undertakings suggest that only 2 regulators produce such a report, which is checked by an impartial third party only in 1 country. In sum, this deficiency, albeit important, does not appear to considerably affect the accountability of the regulator, whose operations are characterised by adequate clarity and are publicly detailed.

Moving to the seventh key area (pro-activity and effectiveness), regulators' powers turn out to be rather limited in respect to track access charging schemes. Only 5 regulators (out of 14) have the possibility of approving the totality of these schemes, even though the Recast (Article 56, paragraph 6) says that the regulatory body shall ensure that charges set by the infrastructure manger comply with the principles set out in the Recast. Regulators seem to play an active role only when connected complaints are raised and non-discrimination needs to be preserved (as previously highlighted): nonetheless this may be rare in those numerous contexts where competition is lacking. This function pertaining to the approval of all charging schemes is in need of uniformity across Europe: the lack of power in this respect means that regulatory capabilities are not being fully exploited (as attested to some extent also by the results emerging in the previous key areas). The relevance of the control over the access charges set by the infrastructure manager is particularly important as more newcomers enter railway markets. This is corroborated by the literature, as for instance in the work by ÁlvarezSanJaime et al. (2016), who set out an imperfect competition model to study the charges' effects on subsequent competition and demand levels for high speed routes. On the other hand, a positive picture emerges regarding the enforcement powers accorded to regulatory decisions: all the regulators (14) are able to produce legally binding decisions, and the majority (11) can impose penalties, in most cases hitting a certain proportion of the sanctioned company's turnover.

A similarly unbalanced trend is identified in the last key area (area 8), where the monitoring powers of the regulators are investigated, with particular reference to the activity of the infrastructure managers. The position here is, perhaps, unexpected, considering the new powers given by the Recast in this area. Only 4 regulators (out of 14) play a role in monitoring the performance (quality of the infrastructure) and efficiency of the infrastructure managers, while 3 of these and 1 other can require 
data to support their regulatory role ${ }^{13}$. There are only 2 countries in which the agencies (alone or with the government) regulate the performance and the efficiency of the infrastructure manager (that is, more than simply a monitoring role), as opposed to the alternative situation (7 countries) where exclusively the government plays this role through a multi-annual contract, which is present in 11 countries (out of 15). While diverse activities are in place in a number of countries - covering tasks such as audits, investigations, notification of warnings and, in some cases, even the possibility of affecting infrastructure managers' powers - these are argued not to embrace the full range of possibilities conferred on regulators by the relevant legislation. Influencing the efficiency and quality of infrastructure managers' performance ultimately produces potential repercussions on costs, access charges, competition and demand levels, and this seems to be mainly achieved thanks to the enforcement of multi-annual contracts (by governments) around Europe.

The findings suggest that regulators' potential has decisively improved in recent years but cannot be considered to be fully exploited yet. Further strengthening the powers and role of economic regulators would seem to be beneficial, especially in light of the findings in Smith et al. (2015), where stronger economic regulation was associated with the improved efficiency performance of European railway systems. Specifically, and based on our survey, we consider that the following areas of regulatory activity require particular attention going forward if the full benefits of independent regulation are to be captured:

- $\quad$ Tendering procedures are rarely implemented for the allocation of passenger routes covered by public service contracts and, where implemented, regulators only in isolated cases seem to be asked to collaborate in the designing stages;

- The growing diffusion of regulatory boards, as opposed to individual regulators, is to be encouraged for the purpose of attaining more shared and better founded decisional processes;

- In view of the growing liberalisation of rail markets across Europe, the expanding trend for human and financial resources available to regulators needs to continue;

\footnotetext{
${ }^{13}$ Another 2 regulators can access this data only for individual cases (not as a general practice).
} 
- $\quad$ Track access charging schemes are approved by only a small number of regulators around Europe, even though regulators' response seem strong in case of appeals;

- Similarly, regulators' role is limited in relation to monitoring and enforcing the infrastructure manager's quality and efficiency.

Counter-arguments may justify some of these deficiencies. Utilising direct awards instead of tendering procedures may be determined by the lack of competitive forces, budgetary constraints may limit the allocation of more resources to regulatory operations, and the control of the infrastructure managers' activities may be ensured by the presence of multi-annual contracts between these bodies and governments. Indeed, the Recast leaves the decision on whether the regulatory body or the government is responsible for exerting pressure to reduce costs with the member states. Nonetheless, the empirical results contained in Smith et al. (2015) show that strong regulation plays a role in reducing the costs of a railway system. Various strategies may be therefore delineated in order to foster this role. Gains in efficiency may arise from reshuffling railway governance arrangements: governments seem to play a strong role in many contexts where instead regulatory bodies' expertise may be exploited. Regulatory intervention may be enhanced for the promotion of competition, beyond the current activities on non-discrimination and towards the designing of tenders. In addition, enforcement of efficient practices on the part of the infrastructure managers may be pursued, carefully avoiding duplication with safeguarding mechanisms already envisaged by multi-annual contracts. However, there would still appear to be advantages in having the role of incentivising and enforcing efficiency improvements played by a body that is independent of government, and this approach is generally adopted in economic regulation in the UK for example.

\section{Conclusions}

The framework for economic regulation of Europe's railways has undergone major reform in recent years, particularly after the 2012 Recast. The previous literature assessing the impact of rail reforms in Europe has focused mainly on the effects of competition and vertical structure, and has paid relatively little attention to regulatory reforms Those approaches did not consider in any depth the question of precisely how economic regulation is implemented, or which aspects of the regulatory 
role are the most developed or most potent. Importantly, the previous literature does not cover the period since the critical Recast reforms post-2012.

This paper develops and complements the previous literature by offering a bottom-up, indepth, and up-to-date assessment of the state of economic rail regulation in Europe as of October 2014. We develop a questionnaire addressed to 14 rail regulators in Europe (additionally to a sample of regulatees for specific questions where appropriate; see sections 4 and 5). This approach enabled the collection of updated and first-hand evidence on the current status of rail regulation across Europe, which is particularly valuable given the key reforms implemented in recent years. The questionnaire was based on an extensive review of the literature on what constitutes ideal regulatory characteristics, giving our approach a theoretical underpinning.

We find that a positive narrative emerges in respect of regulatory independence. Ensuring independence from government, by taking regulators outside transport ministries, was a key aim of the 2012 Recast, and this has been implemented in all cases based on our survey. From a procedural perspective, rail regulation by boards (rather than individuals) is becoming more prevalent across Europe, and in general the use of fixed term appointments further enhances independence by reducing the scope for regulatory capture. It is also the case that many regulators have developed considerable expertise and longevity, backed by increased staff numbers and resourcing. Regulators are also found generally to be able to produce legally binding decisions and impose penalties. All of the above contribute to ensure the stability, predictability and transparency of rail regulation in Europe.

It is also clear that regulators are responding quickly to complaints and that nondiscriminatory access is not considered to be a problem either by regulators or the railway undertakings questioned. This suggests that, in principle, those markets which are currently open to competition should be offering a level playing field to new entrants. As a caveat to this point, our survey did not cover new entrants, who may have offered an alternative perspective; though we note that whilst regulators respond to complaints quickly, they have received very few in general. This finding further supports the existence of a level playing field within European railways, where competition is permitted. 
Of course, most passenger markets are not currently open to competition, with direct awards for public service contracts the dominant method in most countries; though this is expected to change with forthcoming legislation (the governance and market opening pillars of the $4^{\text {th }}$ Railway package). However, currently, where competitive tendering is carried out, regulators are not playing a significant role in that process.

There are two, additional and key aspects where it appears that the regulatory role is not well developed in general across Europe. Firstly, and surprisingly, despite the legislative requirement for economic regulators to ensure that track access charges comply with the principles of the Recast, the regulatory role seems to be generally reserved only for dealing with complaints. Secondly, although the Recast sets out the possibility for regulators to play an important role in regulating the efficiency and quality performance of infrastructure managers, this happens only rarely. In the main, the efficiency, financial equilibrium and quality of infrastructure managers is addressed by multi-annual contracts between the companies and government. We consider that there could be considerable benefits from having this role played by an independent regulatory body, as occurs in economic regulation of other sectors (e.g. utilities in the UK and elsewhere).

In conclusion, whilst there are many positive aspects, we see that rail economic regulators in Europe could be playing a much greater role in regulating the efficiency and quality of infrastructure managers, and potentially taking a greater role in the designing stages of passenger market opening. Approval of track access charges is a key role where regulators appear to be reactive, rather than proactive in general. Finally, some of the positive trends on regulatory boards and resourcing of regulators need to be reinforced and see wider diffusion. A key area for future research lies in seeking a deeper understanding of the interdependencies between railway structure, competition and economic regulation. This future research strand may clarify why ideal rail regulatory practices are more or less implemented in certain countries, which is key to justifying the appropriate resources for rail regulatory activities across Europe. 


\section{Acknowledgments}

The authors thank the members of the Community of European Railway and Infrastructure Companies (CER) Economics Group and the Independent Regulators' Group - Rail (IRG) Charges Working Group, as well as the individual regulators contacted directly, for the valuable feedback and responses offered to our questionnaire and research. We are grateful for the support of Miguel Amaral at the French rail and road regulatory body (ARAFER), who hosted a presentation of our research at IRG. Valerio Benedetto acknowledges the Doctoral funding from the Economic and Social Research Council (ESRC, grant number: ES/J500215/1), which had no involvement in the preparation and submission of this work. Responsibility for conclusions drawn is solely that of the authors.

\section{References}

Álvarez-SanJaime, O., P. Cantos-Sanchez, R. Moner-Colonques and J. J. Sempere-Monerris (2016): Rail access charges and internal competition in high speed trains, Transport Policy, 49, 184-195, http://dx.doi.org/10.1016/j.tranpol.2016.04.006.

Beria, P., F. Ramella, and A. Laurino (2015): Motorways economic regulation: A worldwide survey, Transport Policy, 41, 23-32, http://dx.doi.org/10.1016/j.tranpol.2015.03.010.

Crozet, Y., C.A. Nash and J. Preston (2012): Beyond the quiet life of a natural monopoly: Regulatory challenges ahead for Europe's rail sector, Policy paper for Centre on Rail Regulation in Europe (CERRE).

Fleck, R.K. (2000): When Should Market-Supporting Institutions Be Established?, Journal of Law, Economics, \& Organization, 16 (1), 129-154, http://dx.doi.org/10.1093/jleo/16.1.129.

Gassner, K. and N. Pushak (2014): 30 years of British utility regulation: Developing country experience and outlook, Utilities Policy, 31, 44-51, http://dx.doi.org/10.1016/j.jup.2014.09.003.

IBM and Kirchner, C. (2002, 2004, 2007 and 2011): Rail Liberalisation Index. Comparison of the Status of Market opening in the Rail Markets of the Member States of the European Union, Switzerland and Norway, Berlin. 
IBM Business Consulting Services (2006): Rail Regulation in Europe. Comparison of the status quo of the regulation of rail network access in the EU-25 countries, Switzerland, and Norway, Zurich.

OECD (2000): Telecommunication regulations: Institutional structures and responsibilities, $O E C D$ Digital Economy Papers, No. 48, OECD Publishing.

OECD/ITF (2011): Better Economic Regulation: The Role of the Regulator, ITF Round Tables, No. 150, Paris: OECD Publishing.

Smith, A.S.J., V. Benedetto and C.A. Nash (2015): The impacts of economic regulation on the efficiency of European railway systems, in: Thredbo $14-14^{\text {th }}$ International Conference Series on Competition and Ownership in Land Passenger Transport, 30 August/3 September, Santiago.

The Fourth Railway Package - completing the single European railway area to foster European competitiveness and growth, COM (2013) 25, final.

van de Velde, D., C.A. Nash, A.S.J. Smith, F. Mizutani, S. Uranishi, M. Lijesen and F. Zschoche (2012): EVES-Rail - Economic effects of Vertical Separation in the Railway Sector, Brussels: Community of European Railways.

Wetzel, H. (2008): European Railway Deregulation. The Influence of Regulatory and Environmental Conditions on Efficiency, Working Paper 86, Institute of Economics, Leuphana University of Lüneburg. 